\title{
Research is vital to progress healthcare more now than ever
}

\author{
DOI: $10.7861 /$ fhj.ed.8.2.1
}

Welcome to this edition of the Future Healthcare Journal, the first in a purely online format. Do please feed back on the new style.

The theme of this issue is research. I am enormously grateful to Cheng-Hock Toh, the Royal College of Physicians' (RCP's) academic vice president, and Paul Stewart, The Academy of Medical Sciences' vice president (clinical), for commissioning a spectrum of articles that emphasise, in their own words, that research 'must never be the same again'. The collective experience of the authors is vast and their words insightful, deserving both reading and reflection.

As usual we also have a comprehensive spectrum of other articles covering original research, quality improvement and opinion. The dominant theme, of course, remains COVID-19. As an editorial board, we have been more reflective about what the Future Healthcare Journal should publish and have aimed to accept articles describing collective multicentre experience or adding real insight into how we should manage COVID-19 itself, future pandemics in general and healthcare in the new (digital) age.

I am always pleased to publish work from around the world and the paper from Marcel Spanier et al looks at changes in practice for COVID-19 within a Dutch hospital. ${ }^{1}$ There are many similarities in our UK healthcare systems and we can certainly learn from each other.

In terms of broad healthcare, the paper from James Henderson et al is noteworthy. ${ }^{2}$ I must declare a bias as it comes from my own institution. They describe how the involvement of a geriatrician to manage patients' post-cardiac intervention has been effective in improving patient journeys. I see this as an extension of the nowestablished practice of ortho-geriatrics. It is increasingly clear that for complex, often frail, patients with multiple conditions, once a single-organ intervention has been completed there are benefits to managing ongoing care through a multidisciplinary team led by a broad-based physician. It is whispered in hospital corridors (and was part of the Future Hospital Programme) that perhaps we should change the model of care for all surgical patients to be primarily managed by physicians or geriatricians on a day-to-day basis. ${ }^{3}$ This paper progresses that idea. But where is the evidence for this? Well, we now know from COVID-19 that we can undertake intervention trials with simple protocols, focused end points and rapid recruitment. We must start to transfer this learning from the pandemic to wider aspects of medical care, a theme further explored by Guilherme Pessoa-Amorim et al in their paper in the themed section on research. ${ }^{4}$

I would also like to add a comment about the paper by Fawz Kazzazi et al entitled 'What can we learn from supermarkets...' 5 The authors try to apply supply practices in supermarkets to maintaining adequate and regular supplies of blood culture bottles. Over my career we have frequently attempted to apply practices from private industry to the health service; I think the results have been mixed, but we need to be open minded and receptive to learning from the wider world beyond healthcare.

I am full of uncertainties about the future of the health service, which of the transformations we have seen will continue and which will not, how we will manage the huge burden of disease that has not been addressed for well over a year and how in particular our workforce will fare. I am not alone in hearing dichotomous instructions from trusts such as to implement cost improvement programmes ... and prepare for a third wave. One can easily become bewildered and confused. Research will be vital to make sense of our healthcare environment, which is why the themed articles in this issue are so important. This is exemplified in the must-read paper by Prof Dame Sally Davies and Claire Oxlade in the research section entitled 'Innovate to secure the future: the future of modern medicine. 6

Through all of this turmoil, it is essential that we keep patients at the centre of our care, and their safety at the heart of all that we do. For this reason, the theme of our next issue will be safety, in all its manifestations through the journeys of our patients and the welfare of our workforce.

I hope you enjoy this issue of the Future Healthcare Journal and feedback and engage with us through email (fhj@rcp.ac.uk), social media (@FutureHealth]) and, in particular, by joining us in our Twitter debates (\#RCPjournalclub).

\section{Dr Kevin Fox} Editor-in-chief

\section{References}

1 Spanier M, Kerkvliet K, Veeman A. Principles and practice of deploying a flexible physician workforce for COVID-19 care wards from a Dutch hospital. FHJ 2021;8:e311-3.

2 Henderson JWM, Sweeney M, Dani M, Levy S. Geriatrician-led care model in frail cardiology patients reduces re-admissions. $\mathrm{FHJ}$ 2021;8:e299-301.

3 Royal College of Physicians. Future Hospital Programme: Delivering the future hospital. RCP, 2017. www.rcplondon.ac.uk/projects/ outputs/future-hospital-programme-delivering-future-hospital

4 Pessoa-Amorim G, Campbell M, Fletcher L et al. Making trials part of good clinical care: lessons from the RECOVERY trial. FHJ 2021;8:e243-50.

5 Kazzazi F, Kazzazi D, Kukendra-Rajah K, Basarab M. What can we learn from supermarkets? An application of the Poisson distribution (order-up-to) model to improve blood culture bottle supplies. FHJ 2021:8:e283-7.

6 Davies SC, Oxlade C. Innovate to secure the future: the future of modern medicine. FHJ 2021:8:e251-6.

$\begin{array}{ll}\text { Members of the editorial board } & \\ \text { Suzie Bailey } & \text { Linford Fernandes } \\ \text { Kate Bascombe } & \text { Kevin Fox } \\ \text { Rodger Charlton } & \text { Linda Milnes } \\ \text { Laura Chenevert } & \text { Rose Penfold } \\ \text { Mohsin Choudry } & \text { Anenta Ramakrishnan } \\ \text { John Dean } & \text { Christian Subbe } \\ \text { Julia Ellis } & \text { Joanna Szram }\end{array}$

Mark Temple Louella Vaughan Emma Vaux Sheena Visram Katharine Warburton 